\title{
NOVAS REGRAS DO BASQUETEBOL: ESTUDO DE CASO SOBRE A PERCEPÇÃO DE JOGADORES DE UMA EQUIPE PROFISSIONAL
}

\author{
Heitor de Andrade Rodrigues, Universidade Federal de Goiás - UFG, Goiânia, Goiás - \\ Brasil \\ Thiago Leonardi, SENAI, Americana, São Paulo - Brasil \\ Roberto Rodrigues Paes, Universidade Estadual de Campinas - UNICAMP, Campinas, \\ São Paulo - Brasil
}

\section{RESUMO}

Em abril de 2010, o Comitê Central da Federação Internacional de Basquetebol (FIBA) aprovou algumas alterações nas regras da modalidade. Nesse contexto, o objetivo do presente estudo foi investigar a percepção de seis jogadores de uma equipe profissional quanto às mudanças provocadas no contexto do jogo de basquetebol, em decorrência da alteração das regras. O método utilizado é de natureza qualitativa, na perspectiva de um estudo de caso realizado em abril de 2011. Para coleta dos dados utilizou-se a entrevista semi-estruturada e para análise optou-se pela técnica do Discurso do Sujeito Coletivo (DSC). Os resultados apontam que a alteração mais relevante, na percepção dos atletas, foi o aumento da distância da linha dos três pontos, a qual provocou um aumento do espaço de jogo, facilitando as ações táticas ofensivas.

Palavras-Chaves: Esportes; Basquetebol; Ensino.

\section{NEW BASKETBALL RULES: A CASE STUDY ON THE PERCEPTION OF PLAYERS OF A PROFESSIONAL TEAM}

\begin{abstract}
In April 2010, the Central Committee of the International Basketball Federation (FIBA) has approved some changes to the rules of the sport. In this context, the aim of this study was to investigate the perception of six players of a professional team of the changes brought about in the context of the game of basketball, due to the change of rules. The method used is qualitative in nature, in view of a case study conducted in April 2011. The data collection was used semi-structured interview and was chosen for analysis by the technique of Collective Subject Discourse (CSD). The results show that the most relevant change was the increase in distance from three point line, which caused an increase in game space, facilitating the actions offensive tactics.
\end{abstract}

Key-Words: Sports; Basketball; Education. 


\section{LAS NUEVAS REGLAS DEL BALONCESTO: ESTUDIO DE CASO SOBRE LA PERCEPCIÓN DE LOS JUGADORES DE UN EQUIPO PROFESIONAL}

\section{RESUMEN}

En abril de 2010, el Comité Central de La Federacioón Internacional de Baloncesto (FIBA) ha aprobado cambios en lãs reglas de este deporte. En este contexto, el objetivo de este estudio fue investigar la percepción de seis jugadores de un equipo profesional de los cambios producidos en el contexto del juego de baloncesto, debido al cambio de las reglas. El método utilizado es de naturaleza cualitativa, com el enfoque de la investigación exploratória. La recolección de datos se utilizo la entrevista semiestructurada y fue elegido para el análises por la técnica del Discurso del Sujeto Colectivo (DSC). Los resultados muestran que el cambio más relevante fue el aumento de la distancia de três puntos, lo que provoco um aumento en el espacio de juego, lo que facilita lãs acciones tácticas ofensivas.

Palabras-Clave: Deportes; Baloncesto; Enseñanza. 


\section{INTRODUÇÃO}

No ano de 2010, o Comitê Central da Federação Internacional de Basquetebol (FIBA) aprovou algumas alterações nas regras do basquetebol, as quais provocaram mudanças no desenvolvimento do jogo. Dentre as alterações destacam-se o aumento da distância da linha dos três pontos, a modificação do formato da área restritiva (garrafão), a inclusão de áreas semicirculares próximas às cestas, a inclusão de linhas de reposição de bola no ataque e alteração da regra dos 24 '.

As mudanças de regras no esporte são parte do processo de profissionalização, mercantilização e espetacularização desse fenômeno sociocultural. Tais mudanças podem ser atribuídas a diversos fatores, dentre eles chama a atenção o interesse em aumentar a imprevisibilidade do resultado de jogos e das disputas, e mesmo o interesse em adequar os tempos e espaços dos esportes às necessidades da programação midiática. ${ }^{1-2}$

Os exemplos de mudança de regra são os mais diversos. O voleibol, por exemplo, modificou seu sistema de pontuação deixando de utilizar o fator vantagem nas disputas pelo ponto, passando a pontuar todas as bolas que tocam o solo. $\mathrm{O}$ basquetebol em outra oportunidade já havia modificado o tempo de posse de bola para finalizar em cesta de 30' para 24'. Mais recentemente, o futsal alterou diversas regras do jogo, com atenção especial para a atuação do goleiro em situações de recuo de bola e sua participação na condição de goleiro-linha, permitida apenas em sua quadra de ataque.

As modificações de regras nos esportes coletivos em geral e no basquetebol em específico impõem aos jogos novas demandas técnico-táticas, as quais modificam a forma como os jogadores percebem e atuam no jogo. A percepção e/ou leitura que um jogador faz a cada momento tem influência sobre sua tomada de decisão. Assim sendo, no contexto do basquetebol, por exemplo, o jogador, envolto pela complexidade e imprevisibilidade que são característicos ao fenômeno esportivo, deve perceber, dentre inúmeros fatores (como a sua distância para o alvo, a bola, o posicionamento/deslocamento de seus companheiros/adversários perante o alvo, dentre outros), quais elementos são primordiais para sua tomada de decisão. ${ }^{3}$

No contexto dessa discussão, considerando a relevância das alterações de regras no esporte, é possível afirmar que as modificações têm sido tão significativas que deveriam 
ser levadas em conta na organização, planejamento, sistematização, aplicação e avaliação de procedimentos pedagógicos no processo de ensino e treinamento do esporte. ${ }^{1}$

Apesar da proeminência dessa temática, ainda constitui-se assunto pouco explorado no âmbito das Ciências do Esporte. Diante desse quadro, a partir de um estudo de caso, o objetivo da presente pesquisa foi investigar a percepção de seis jogadores de uma equipe profissional quanto às mudanças provocadas no contexto do jogo de basquetebol, em decorrência da recente alteração das regras, no ano de 2010.

\section{REVISÃO DA LITERATURA}

O basquetebol é um esporte de cooperação e oposição, com ocupação de espaço comum e participação simultânea, o que indica que se trata de um esporte muito dinâmico, participativo e com uma rede complexa de comunicação entre os indivíduos da mesma equipe e da equipe adversária. As ações dos jogadores de basquetebol ocorrem em espaço compartilhado, espaço esse na maioria das vezes reduzido (meia quadra), no qual ambas as equipes atuam simultaneamente em torno do objeto de jogo, caracterizando situações de ataque e defesa delimitadas pela posse ou não da bola. ${ }^{4}$

Com base no conceito de regras de ação ${ }^{5}$ é possível identificar princípios básicos de atuação tática no basquetebol de acordo com as fases do jogo (ataque/defesa), tais como: a) princípios ofensivos: a criação de linhas de passe, situações de passar e desmarcar-se, conservação da posse da bola, progressão em direção ao alvo adversário objetivando a finalização; b) princípios defensivos: defender entre o atacante e a cesta, dificultar a troca de passes e arremessos, esforçar-se para recuperar a posse da bola. ${ }^{6}$

Ainda em relação à dimensão tática do basquetebol é possível classificar as ações táticas específicas do jogo em individuais, grupais e coletivas. ${ }^{7}$ As ações táticas individuais estão relacionadas à capacidade do jogador de executar suas habilidades pessoais, seja criando situações favoráveis de ataque utilizando os fundamentos de drible, passe e arremesso ou dificultando as ações ofensivas provocando o erro do adversário, dificultando a recepção de bola, conduzindo o jogador em posse de bola para regiões vulneráveis da quadra (linha de fundo e lateral) e diminuindo os espaços para infiltrações, passes e arremessos. No tocante à tática grupal o autor se refere às situações de $2 \times 2$ e $3 \times 3$, com ênfase para as ações Conexões: revista da Faculdade de Educação Física da UNICAMP, Campinas, v. 11, n. 3, p. 147-165, jul./set. 2013. ISSN: 1983-9030 
ofensivas de servir e ir e bloqueio, bem como ações táticas defensivas de ajuda, troca de marcação e saída de bloqueio. Por fim, quanto às ações táticas coletivas $(5 \times 5)$, aponta na defesa os sistemas por zona e individual e no ataque as possibilidades de contra-ataque e ataque posicionado.

Como é possível identificar a partir das contribuições dos autores, o basquetebol é um esporte com características estruturais bastante complexas, o que impõem aos jogadores situações problemas, situações imprevisíveis, as quais podem ser solucionadas a partir de uma diversidade de ações táticas.

Nesse contexto, as regras do jogo são elementos fundamentais a potencializar ou limitar as ações dos jogadores, já que é baseado nelas que os mesmos tomam suas decisões. As regras do jogo são um dos fatores que influenciam nas regras de ação dos jogadores durante a prática da modalidade. $\mathrm{O}$ teor das regras permite aos jogadores avaliar os movimentos e ações táticas que podem ser criados ou executados, bem como os que deverão ser evitados, respeitando os princípios operacionais intrínsecos aos esportes coletivos. Portanto, as regras são elementos modeladores da ação dos jogadores, com certo grau de padronização e, ao mesmo tempo, certo grau de liberdade de escolha.

Institucionalmente, no caso específico do basquetebol, a cada quatro anos, aproximadamente, as regras sofrem mudanças a fim de acompanhar a evolução do jogo nos seus aspectos físicos e técnico-táticos e nas várias ações administrativas necessárias. ${ }^{8}$

Assim, parece fundamental investigar as alterações das regras do basquetebol e os possíveis desdobramentos dessas alterações na estrutura do jogo, bem como nas ações dos jogadores.

Mas quais foram efetivamente as principais alterações das regras do basquetebol? Em abril de 2010, o Comitê Central da Federação Internacional de Basquetebol (FIBA) aprovou algumas alterações nas regras da modalidade, as quais entraram em vigor no mês de outubro do mesmo ano. Na Figura 1, extraída do site oficial da FIBA, apresentamos o desenho de uma quadra de basquetebol, já com as medidas e especificações atualizadas.

Conexões: revista da Faculdade de Educação Física da UNICAMP, Campinas, v. 11, n. 3, p. 147-165, jul./set. 2013. 


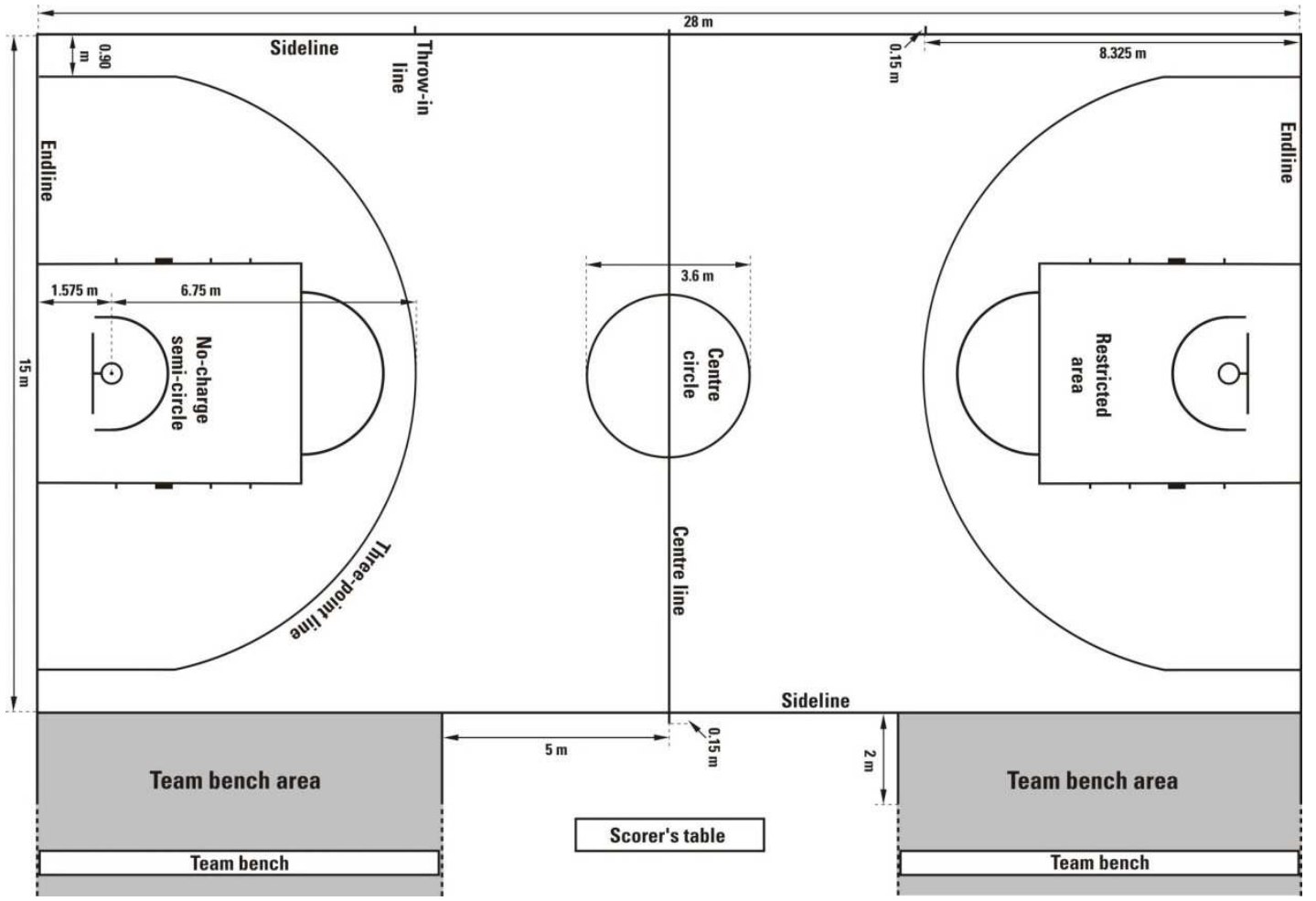

Figura 1 - Quadra de basquetebol padrão FIBA a partir de 2010.

Fonte: Adaptado de:

http://www.fiba.com/downloads/Rules/2012/OfficialBasketballRules2012.pdf. 9:6

A atual demarcação nos permite identificar as principais mudanças, senão vejamos:

1- Alteração do formato da área restritiva (garrafão) de um trapézio para um retângulo, o que aumenta a região vulnerável a violações relacionadas à ocupação desse espaço por mais de três segundos;

2- Inclusão de áreas semicirculares dentro das áreas restritivas, nas quais a carga ofensiva não será considerada faltosa;

3- Aumento da distância da linha demarcatória dos três pontos de 6,25 metros para 6,75 metros, o que promove uma maior abertura do sistema defensivo quando o objetivo é diminuir as chances do adversário em converter cestas de 3 pontos;

4- Inclusão de linhas de reposição de bola na lateral à 8,325 metros da linha de fundo, local onde as reposições serão cobradas, nos últimos dois minutos da partida e dos períodos extras. Ou seja, no caso de uma equipe ter o direito a uma reposição de bola em sua quadra defensiva nos períodos do jogo citado 
acima, a reposição será realiza na quadra de ataque à 8,325 metros da linha de fundo, e não mais na linha central.

Além dessas quatro alterações bastante visíveis tivemos também uma mudança que não é identificável a partir da análise das linhas demarcatórias da quadra, a alteração da regra dos 24 segundos. Com a alteração da regra dos 24 segundos a reposição de bola administrada no campo de ataque terá o cronometro ajustado para 14 segundos quando restarem 13 ou menos segundos para o ataque ou serão mantidos quando restarem 14 ou mais segundos para finalização do ataque. Válido ressaltar que as reposições administradas na quadra de defesa terão o relógio ajustado para 24 segundos.

\section{PROCEDIMENTOS METODOLÓGICOS}

A metodologia utilizada é de natureza qualitativa, tendo sido realizado um estudo de caso com uma equipe profissional de basquetebol, em abril de 2011. Os estudos de caso surgem da necessidade de compreender fenômenos sociais complexos, permitindo investigações significativas de eventos da vida real. ${ }^{10}$ No delineamento dos estudos de caso considera-se relevante respeitar quatro fases específicas, dentre elas, a delimitação da unidade/caso; coleta dos dados; seleção, análise e interpretação dos dados; e elaboração de relatório final. $^{11}$

Fizeram parte deste estudo 6 jogadores de basquetebol profissional, de uma equipe participante da Copa Brasil (2010/2011), sendo 2 armadores (ambos com características para ocupar a posição 1), 2 laterais (ambos com características para ocupar a posição 3) e 2 pivôs (sendo um acostumado à posição 4 e o outro à posição 5). Portanto, podemos afirmar que todos os jogadores entrevistados passaram pela etapa de especialização na modalidade, tendo conhecimento sobre os princípios ofensivos e defensivos do jogo de basquetebol, tal como explicitado nas respostas dadas às entrevistas realizadas com os mesmos.

Para coleta dos dados utilizou-se a entrevista semi-estruturada, o que permitiu partir de um roteiro básico de questões, aprofundando e esclarecendo as informações que se julgou necessário, ou seja, caso as respostas fossem insuficientes aos propósitos do estudo o 
pesquisador poderia explorar melhor as questões com a intenção de obter informações mais detalhadas.

As entrevistas foram realizadas individualmente com cada um dos jogadores, gravadas com auxílio de gravador (Sony ICD-PX820) e transcritas integralmente com auxílio do programa Via Voice IBM.

Para descrição e análise dos dados obtidos por meio das entrevistas optou-se pela utilização da técnica do Discurso do Sujeito Coletivo (DSC), a qual se constitui como proposta de organização e tabulação de dados qualitativos obtidos especialmente por meio de depoimentos. $^{12}$

A construção do DSC se da a partir da utilização de alguns recursos ou figuras metodológicas, mais especificamente, a partir da identificação no discurso dos entrevistados de Expressões-Chave (ECH) e Ideias Centrais (IC). As ECH são transcrições literais do discurso, pedaços, trechos que correspondem às questões da pesquisa, são o conteúdo/substância. Já as IC são o nome/a marca do discurso, as quais possibilitam agrupar as ECH em torno de uma ideia particular, uma ideia comum, uma ideia central, que permite reduzir a polissemia do discurso. Portanto, o pesquisador deve ler atentamente cada uma das entrevistas, identificar em cada uma delas as ECH, apontar as IC e a partir desse exame minucioso dos discursos individuais produzir o DSC, o qual representa um discurso-síntese que expressa o pensamento coletivo.

Importante ressaltar que o instrumental do DSC foi idealizado para fase descritiva da pesquisa, cabendo ao pesquisador o esforço de interpretação dos dados a luz do referencial teórico.

Válido destacar que a pesquisa foi realizada com o consentimento dos indivíduos envolvidos e para tanto os mesmos foram esclarecidos sobre os possíveis riscos e o direito a desistir a qualquer momento. Além disso, obteve-se a aprovação de seus propósitos e

Conexões: revista da Faculdade de Educação Física da UNICAMP, Campinas, v. 11, n. 3, p. 147-165, jul./set. 2013. ISSN: 1983-9030 
procedimentos junto ao Comitê de Ética em Pesquisa da Faculdade de Ciências Médicas da Unicamp (CAAE n ${ }^{\circ}$ 01014812.6.0000.5404).

\section{RESULTADOS E DISCUSSÃO}

Na descrição dos resultados optou-se por apresentar o Discurso do Sujeito Coletivo (DSC) produzido a partir da análise das informações de cada questão, com exceção da questão número um, a qual apresenta dados mais objetivos, o que não permitiu a construção do DSC.

Os dados obtidos foram apresentados de forma descritiva com o auxílio de tabelas e quadros para cada questão, sendo a tabela destinada aos resultados das Ideias Centrais (IC) e os quadros aos resultados do DSC. Complementando os dados apresentados nas Tabelas optou-se pela descrição exaustiva dos dados no corpo do texto procedendo, a partir disso, a discussão dos mesmos.

Para iniciar a reflexão sobre a alteração de regra no basquetebol os seis jogadores foram questionados se tinham conhecimento das principais alterações realizadas e implementadas no ano de 2010.

De acordo com os dados obtidos (TABELA 1) foi possível identificar que todos os jogadores recordaram-se da alteração da distância da linha de três pontos, cinco jogadores recordaram-se da inclusão do semicírculo dentro da área restritiva, três recordaram-se da mudança no formato da área restritiva, apenas um recordou a alteração da regra dos 24 segundos e nenhum jogador recordou a inclusão de linhas de reposição de bola no ataque.

Tabela 1 - Número de ocorrência das alterações das regras, na lembrança dos sujeitos

\begin{tabular}{|c|c|c|}
\hline REGRA & OCORRÊENCIA & SUJEITOS \\
\hline Distância da linha dos três pontos & 6 (seis) & $(\mathrm{S} 1, \mathrm{~S} 2, \mathrm{~S} 3, \mathrm{~S} 4, \mathrm{~S} 5, \mathrm{~S} 6)$ \\
\hline Inclusão do semicírculo dentro da área restritiva & 5 (cinco) & $(\mathrm{S} 1, \mathrm{~S} 2, \mathrm{~S} 3, \mathrm{~S} 4, \mathrm{~S} 5)$, \\
\hline Mudança no formato da área restritiva & 3 (três) & $(\mathrm{S} 2, \mathrm{~S} 5, \mathrm{~S} 6)$ \\
\hline Mudança da regra dos 24 segundos & 1 (uma) & (S3) \\
\hline Inclusão de linhas de reposição de bola na lateral & 0 (zero) & \\
\hline
\end{tabular}

Conexões: revista da Faculdade de Educação Física da UNICAMP, Campinas, v. 11, n. 3, p. 147-165, jul./set. 2013. ISSN: 1983-9030 
Esses dados permitem algumas inferências, a primeira delas diz respeito à discrepância entre o número de indicações da alteração da distância dos três pontos, recordada por todos os jogadores, e o baixo número de indicações ou ausência delas para a regra dos 24 segundos e a inclusão das linhas de reposição de bola no ataque. Tais resultados podem indicar uma maior relevância da alteração da distância dos três pontos em relação a atuação dos jogadores na partida e consequentemente menor relevância daquelas pouco lembradas.

Ao mesmo tempo os dados indicam certo desconhecimento sobre as principais alterações da regra, já que a pergunta exigiu dos jogadores a recordação das principais alterações e não um juízo de valor sobre a alteração mais relevante ou significativa. Parece que os jogadores não tiveram a oportunidade de refletir e discutir, dentro da equipe, as alterações da regra no ano de 2010 e seus possíveis desdobramentos para o jogo. Assim, é possível inferir que as aprendizagens sobre as regras e consequentemente suas opiniões sobre elas vão sendo construídas no contexto prático de vivência do jogo, em um comportamento inicialmente intuitivo e menos por meio de debates com o grupo de trabalho.

Complementando o questionamento sobre o conhecimento das alterações das regras interessa saber as alterações mais significativas (TABELA 2, QUADRO 1), no sentido de identificar aquelas que provocaram as mudanças mais relevante no contexto do jogo, na percepção dos jogadores.

Tabela 2 - Definição e descrição das ideias centrais e do número de ocorrências para a questão: Em sua opinião, qual foi a alteração mais significativa das regras? Por quê?

\begin{tabular}{lll}
\hline IDEIAS CENTRAIS (IC) & OCORRÊNCIA & SUJEITOS \\
\hline Aumento da distância da linha dos três pontos & 6 (seis) & (S1, S2, S3, S4, S5, S6) \\
Reposição de bola na lateral nos minutos finais da partida & 1 (uma) & (S1) \\
\hline
\end{tabular}

Conexões: revista da Faculdade de Educação Física da UNICAMP, Campinas, v. 11, n. 3, p. 147-165, jul./set. 2013. ISSN: 1983-9030 
Quadro 1- Descrição das ideias centrais (IC) e do discurso do sujeito coletivo (DSC) referente à questão: Em sua opinião, qual foi a alteração mais significativa das regras? Por quê?

\section{IDEIAS CENTRAIS (IC) DISCURSO DO SUJEITO COLETIVO}

\begin{tabular}{ll}
\hline $\begin{array}{l}\text { Aumento da distância da linha } \\
\text { dos três pontos }\end{array}$ & Ainha de três. Ficou mais difícil arremessar as bolas, porque \\
& normalmente os jogos do ano passado estavam parecendo disputa de três \\
& pontos. Estava uma vida toda a arremessar de uma certa distância, \\
& esporadicamente você acabava fazendo o arremesso mais longe, mas não \\
& com a mesma frequência agora que tem a linha demarcada. Ficou mais \\
& aberto, para infiltrar mais. Porque faz a defesa abrir, faz subir a defesa, \\
& aumenta os espaços. A ajuda está um pouco mais longe, o lado oposto está \\
& um pouco mais longe. Se você souber explorar bem os espaços o trabalho \\
& de pick (jogo de dupla) fica mais facilitado. O pessoal está selecionando \\
& mais os arremessos e também está abrindo espaço, como aumentou a linha \\
& de três pontos abre espaço para a infiltração, abre espaço para o jogo \\
& embaixo com os pivôs, o jogo ficou mais aberto, ficou mais difícil para se \\
& marcar o adversário. \\
A questão da reposição não parece nada, mas no final do jogo isso muda \\
todo contexto, no jogo pau a pau você pode pedir um tempo e sair lá na \\
frente e conseguir elaborar uma jogada. \\
$\begin{array}{l}\text { Reposição de bola na lateral nos } \\
\text { minutos finais da partida }\end{array}$
\end{tabular}

$\mathrm{Na}$ opinião do Sujeito Coletivo (SC) as alterações mais significativas nas regras do basquetebol foram o aumento da distância da linha dos três pontos (S1, S2, S3, S4, S5, S6) e a reposição de bola a 8,325 metros da linha de fundo nos últimos dois minutos da partida e períodos extras $(\mathrm{S} 1)$.

Com relação a linha de três pontos, no que diz respeito ao ataque, houve um aumento do espaço de jogo facilitando as ações ofensivas. Por outro lado, o aumento da distância da linha dos três pontos dificultou os arremessos de longa distância, prejudicando o aproveitamento de arremessos convertidos.

Já em relação à defesa a mudança na distância da linha dos três pontos dificultou as ações táticas como a ajuda, já que o retorno defensivo após uma ajuda ao companheiro se torna difícil devido a distância entre os jogadores. 
No que diz respeito à regra de reposição de bola identifica-se sua relevância no favorecimento ao ataque nos minutos finais do jogo, já que a posição privilegiada próximo à cesta pode permitir a organização de jogada combinada.

Os dados apresentados na primeira questão e corroborados na segunda questão parecem confirmar a afirmação de alguns autores ${ }^{13}$ quando apontam que os estudos sobre o ensino e treinamento do esporte têm negligenciado a estrutura e complexidade das modalidades a serem ensinadas ou treinadas, já que mesmo os jogadores não demonstram grandes preocupações em analisar de forma minuciosa os possíveis desdobramentos de cada uma das alterações das regras, em especial, surpreende a ausência de reflexão sobre a regra dos 24 segundos e apenas uma reflexão sobre a inclusão de linhas de reposição de bola no ataque.

Avançando na reflexão sobre as alterações mais significativas da regra questionou-se os jogadores se as mesmas favorecem alguma posição no jogo (TABELA 3, QUADRO 2), ou seja, se as mudanças do jogo provocadas pelas alterações das regras favoreceram mais os armadores, os laterais ou os pivôs.

Tabela 3 - Definição e descrição das ideias centrais e do número de ocorrências para a questão: Em sua opinião, a alteração das regras favorece alguma posição específica no jogo (armador, lateral, pivô)?

\begin{tabular}{lll}
\hline IDEIAS CENTRAIS (IC) & OCORRÊNCIA & SUJEITOS \\
\hline Favorece todas as posições no ataque & 6 (seis) & $(\mathrm{S} 1, \mathrm{~S} 2, \mathrm{~S} 3, \mathrm{~S} 4, \mathrm{~S} 5, \mathrm{~S} 6)$ \\
Prejudica os laterais arremessadores & 3 (três) & $(\mathrm{S} 2, \mathrm{~S} 3, \mathrm{~S} 6)$ \\
O semicírculo favorece os pivôs & $1(\mathrm{um})$ & $(\mathrm{S} 5)$ \\
\hline
\end{tabular}

Conexões: revista da Faculdade de Educação Física da UNICAMP, Campinas, v. 11, n. 3, p. 147-165, jul./set. 2013. 
Quadro 2 - Descrição das ideias centrais (IC) e do discurso do sujeito coletivo (DSC) referente à questão: Em sua opinião, a alteração das regras favorece alguma posição específica no jogo (armador, lateral, pivô)?

\section{IDEIAS CENTRAIS (IC) DISCURSO DO SUJEITO COLETIVO}

\begin{tabular}{|c|c|}
\hline $\begin{array}{l}\text { Favorece todas as posições no } \\
\text { ataque }\end{array}$ & $\begin{array}{l}\text { Eu acho que todo mundo tem um benefício, por conta que está mais } \\
\text { aberto. Favoreceu todos porque abriu, o armador da o corte, a ajuda vai } \\
\text { ficar um pouquinho mais difícil. Não tem muita ajuda, você tem facilidade } \\
\text { de corte, o pivô tem facilidade de jogar no um contra um. O armador fica } \\
\text { mais fácil para fazer os passes, porque o jogo vai estar mais aberto. Pivô } \\
\text { fica mais fácil para jogar porque é difícil a ajuda agora no pivô, porque se } \\
\text { sair na ajuda vai tomar chute. Num certo ponto, no time que está mais } \\
\text { acostumado e mete bola de três melhorou. Agora se o time fechar na zona } \\
\text { e a outra equipe não tiver percentual bom de três pontos, prejudica. }\end{array}$ \\
\hline $\begin{array}{l}\text { Prejudica os } \\
\text { arremessadores }\end{array}$ & $\begin{array}{l}\text { No caso das posições, a que está sendo mais prejudicada nesse momento } \\
\text { são os chutadores. Mas acho que é uma questão de tempo também, daqui a } \\
\text { pouco está se adaptando, treinando sempre desse jeito, daqui a pouco está } \\
\text { normal também. }\end{array}$ \\
\hline O semicírculo favorece os pivôs & $\begin{array}{l}\text { Para o pivô aqui (semicírculo na área restritiva) é bom, para jogar mais } \\
\text { forte e não ter falta de ataque. Acho que ajuda, para jogar mais duro ali. }\end{array}$ \\
\hline
\end{tabular}

Verifica-se a partir do DSC que, de forma geral, as alterações beneficiaram todas as posições no jogo ofensivo ( $\mathrm{S} 1, \mathrm{~S} 2, \mathrm{~S} 3, \mathrm{~S} 4, \mathrm{~S} 5, \mathrm{~S} 6)$, já que SC considera que o jogo está mais aberto, todos os jogadores estão encontrando mais espaço para o desenvolvimento das ações de ataque, sendo que os armadores e laterais encontram mais espaços para a realização de passes e infiltrações e os pivôs encontram mais oportunidades de jogo em situações um contra um, principalmente pela dificuldade imposta à defesa em realizar as ações de ajuda. Podemos entender, portanto, que houve uma mudança na ocorrência de regras de ação ${ }^{5}$ durante a partida, já que a alteração nas regras do jogo propiciou o aumento da variabilidade de ação tática dos jogadores em determinadas situações-problema.

Destaca-se ainda, a vantagem proporcionada aos pivôs pela introdução do semicírculo na área restritiva (S5), o que viabiliza aos jogadores de ataque o desenvolvimento de ações ofensivas com maior contato físico, já que o risco de cometer faltas de ataque é menor. Nesse ponto é importante esclarecer que a regra do semicírculo é aplicada nas situações em 
que o jogador de ataque realiza a infiltração das extremidades da quadra em direção à área restritiva, portanto nas situações de jogo, nas quais o pivô recebe a bola próximo à cesta e desenvolve ações (por exemplo, jogar de costas para cesta) para buscar melhores condições de arremesso, não há aplicação da regras, ou seja, a carga ofensiva será penalizada com falta de ataque mesmo na região do semicírculo.

Vale ressaltar que as alterações provocaram prejuízos aos jogadores com características de arremesso de longa distância (S2, S3, S6), ao menos nos primeiros meses da alteração das regras, já que com o transcorrer do tempo os jogadores foram se adaptando à nova distância da linha dos três pontos.

A percepção do SC de que as alterações favoreceram todas as posições, como o caso das situações de um contra um para os pivôs e as infiltrações para armadores e laterais, remetem ao novo posicionamento imposto aos jogadores pelas novas demarcações da quadra, visto que o aumento de 50 centímetros na distância da linha de 3 pontos abriu maior espaço entre os jogadores, ampliando as desvantagens do sistema defensivo, seja ele individual ou por zona, ${ }^{14}$ quais sejam, por exemplo, maior desgaste físico e facilitação de infiltrações, para o sistema individual, e facilidade para arremessos de longas distância bem como para troca de passes, no sistema por zona.

Ainda em relação à discussão do favorecimento provocado pelas alterações, interessa saber se houve um predomínio no favorecimento às ações no ataque ou na defesa (TABELA 4; QUADRO 3).

Tabela 4 - Definição e descrição das ideias centrais e do número de ocorrências para a questão: Em sua opinião, as alterações nas regras favorecem as ações da equipe no ataque ou na defesa?

\begin{tabular}{lll}
\hline IDEIAS CENTRAIS (IC) & OCORRÊNCIA & SUJEITOS \\
\hline Em médio e longo prazo favorece o ataque & 6 (seis) & (S1, S2, S3, S4, S5, S6) \\
Em curto prazo favoreceu a defesa & 4 (três) & (S1, S3, S4, S5) \\
\hline
\end{tabular}

Conexões: revista da Faculdade de Educação Física da UNICAMP, Campinas, v. 11, n. 3, p. 147-165, jul./set. 2013. ISSN: 1983-9030 
Quadro 3 - Descrição das ideias centrais (IC) e do discurso do sujeito coletivo (DSC) referente à questão: Em sua opinião, as alterações nas regras favorecem as ações da equipe no ataque ou na defesa?

\section{IDEIAS CENTRAIS (IC) DISCURSO DO SUJEITO COLETIVO}

Em médio e longo prazo favorece o Acho que mais ataque, o ataque está favorecido. Favorece mais o ataque, ataque não sei se em curto prazo está ajudando a defesa, mas em longo prazo a tendência é ajudar o ataque. O jogo abriu, o jogo está mais aberto. É muito mais difícil para ajudar agora. Se você for batido no um contra um e se o cara ajudar vai sobrar muito livre, antigamente não, ficava mais compacta a defesa.

Em curto prazo favoreceu a defesa No momento está favorecendo a defesa, por ter aumentado a linha, os arremessos não estão tão precisos. A defesa nesse primeiro momento está conseguindo tirar muito proveito de variações defensivas, porque o percentual ainda está baixo da linha dos três pontos. Se você tem uma defesa consistente, ali na zona bem posicionada favorece a saída em contra-ataque.

De acordo com o SC em médio e longo prazo as alterações tendem a favorecer de forma prioritária as ações do ataque ( $\mathrm{S} 1, \mathrm{~S} 2, \mathrm{~S} 3, \mathrm{~S} 4, \mathrm{~S} 5, \mathrm{~S} 6)$, os jogadores insistem no argumento de que o jogo está mais aberto, facilitando as ações táticas de ataque sejam elas individuais, grupais ou coletivas, o que dificulta o trabalho da defesa.

Contudo, apesar do visível favorecimento ao ataque, o SC destaca que no curto prazo as alterações favoreceram a defesa (S1, S3, S4, S5), já que com o aumento da distância da linha dos três o aproveitamento de arremessos de longa distância diminuiu significativamente, o que permitiu às equipes optarem por defesas mais baixas, principalmente aquelas por zona, preservando fisicamente os jogadores, fortalecendo o rebote defensivo viabilizando o recurso ao contra-ataque.

E em relação aos aspectos táticos do basquetebol, as alterações da regra foram capazes de gerar novas demanda táticas ao jogo? Ou seja, as alterações conduziram os jogadores a alterarem suas formas de resolver os problemas do jogo? (TABELA 5, QUADRO4). 
Tabela 5 - Definição e descrição das ideias centrais e do número de ocorrências para a questão: Você identifica alguma mudança na dinâmica tática do jogo a partir das alterações das regras?

\section{IDEIAS CENTRAIS (IC)}

Não houve mudança significativa, apenas pequeno aumento da frequência de ações já existentes

Possibilidades do jogo ofensivo em quatro jogadores abertos

\section{OCORRÊNCIA SUJEITOS}

$(\mathrm{S} 2, \mathrm{~S} 3, \mathrm{~S} 4, \mathrm{~S} 5, \mathrm{~S} 6)$

Quadro 4 - Descrição das ideias centrais (IC) e do discurso do sujeito coletivo (DSC) referente à questão: Você identifica alguma mudança na dinâmica tática do jogo a partir das alterações das regras? Qual

\begin{tabular}{|c|c|}
\hline IDEIAS CENTRAIS (IC) & DISCURSO DO SUJEITO COLETIVO \\
\hline $\begin{array}{l}\text { Não houve mudança } \\
\text { significativa, apenas pequeno } \\
\text { aumento da frequência de } \\
\text { ações já existentes }\end{array}$ & $\begin{array}{l}\text { Na dinâmica acho que não. Não mudou muito não, continua o jogo } \\
\text { do mesmo jeito, só que abriu mais espaço. Antigamente era muito } \\
\text { mais fácil para ajudar, então você conseguia até ajudar em um "pick } \\
\text { and roll", agora se você ajudar você vai tomar um chute porque a } \\
\text { linha de três esta mais longe, dificilmente você vai conseguir } \\
\text { marcar um "pick and roll" bem feito. O "high/low" normal como } \\
\text { tinha antes, jogada com pivô, jogada de dupla, para mim continua } \\
\text { do mesmo jeito, porque isso é o jogo de basquete, porque isso tem o } \\
\text { jogo inteiro. }\end{array}$ \\
\hline $\begin{array}{l}\text { Possibilidades do jogo } \\
\text { ofensivo em quatro jogadores } \\
\text { abertos }\end{array}$ & $\begin{array}{l}\text { Quatro abertos está sendo uma situação que está ficando bem } \\
\text { interessante para jogar. Jogar com um pivô mais versátil, uma } \\
\text { ala/pivô que abra e ataca. Pela questão da ajuda e com quatro } \\
\text { abertos e se você tem quatro jogadores que metem bola de } 3 \text { e joga } \\
\text { no "pick and roll" do lado oposto, esse cara que está marcando o } \\
\text { pivô quatro, para ele ir lá dentro para ajudar no "pick and roll" e } \\
\text { voltar nesse cara está um pouco longe, assim acaba sobrando } \\
\text { bastante chute. Vou até ser mais específico no trabalho de } \\
\text { "high/low", independente quem esteja nas posições sobra chute. Se } \\
\text { os caras estão numa defesa de ajuda e volta ou uma dobra, tenho } \\
\text { percebido que sobra bastante chute, se o cara souber se posicionar. }\end{array}$ \\
\hline
\end{tabular}

Conexões: revista da Faculdade de Educação Física da UNICAMP, Campinas, v. 11, n. 3, p. 147-165, jul./set. 2013. 
No discurso do SC as ações táticas permanecem as mesmas (S2, S3, S4, S5, S6), o que houve foi um aumento na frequência de acontecimento de algumas ações, em especial as ofensivas, tais como, as situações de jogo de um contra um e o jogo de dupla (pick and roll).

Válido destacar ainda a percepção de que o jogo ofensivo com quatro atacantes jogando abertos (S1) pode indicar possibilidades férteis para o jogo de dupla e arremessos de longa e média distância, quando se tem na equipe um pivô versátil capaz de jogar próximo à cesta, mas também com bom aproveitamento em arremessos de média e longa distância.

A partir dessas indicações é possível afirmar que não houve mudanças significativas na forma de atuação tática dos jogadores e das equipes, prevalecendo no DSC os princípios táticos ofensivos, mais especificamente, as ações táticas individuais (1x1) e grupais $(2 \times 2)$.

\section{CONSIDERAÇÕES FINAIS}

No presente estudo buscou-se investigar a percepção de seis jogadores profissionais sobre as mudanças provocadas no contexto do jogo de basquetebol, em decorrência da alteração das regras no ano de 2010.

Os resultados indicam que a alteração mais relevante da regra, na percepção dos jogadores, foi o aumento da distância da linha dos três pontos de 6,25 para 6,75 , tendo em vista que essa alteração provocou um aumento no espaço de jogo, aumentando a distância entre os jogadores, favorecendo as ações táticas ofensivas, como as situações de um contra um e o jogo de dupla e ao mesmo tempo dificultando as ações defensivas, como é o caso das ações de ajuda aos companheiros.

Ressaltaram ainda, que no início da alteração das regras houve uma queda no aproveitamento dos arremessos de longa distância e que tal situação provocou uma mudança de estratégia das equipes, as quais passaram a optar por defesas mais baixas, principalmente, as defesas por zona prejudicando o trabalho dos pivôs.

Conexões: revista da Faculdade de Educação Física da UNICAMP, Campinas, v. 11, n. 3, p. 147-165, jul./set. 2013. 
Por fim, vale salientar a necessidade de estudos mais aprofundados sobre as características estruturais e as incidências táticas do jogo de basquetebol, como é o caso dos estudos interessados nas mudanças geradas pela alteração de regra, no sentido de viabilizar a professores/treinadores conhecimentos relevantes ao processo de ensino e treinamento esportivo.

\section{REFERÊNCIAS}

${ }^{1}$ PAES, R. R. Pedagogia do esporte: ensino, vivência e aprendizagem dos jogos coletivos. In: CONGRESSO INTERNACIONAL DE DEPORTES DE EQUIPOM 2., 2009. La Coruña. Anais... La Coruña: Centro de Formación de Alto Rendimiento, 2009. Disponível em: <http://www.altorendimiento.com/es/congresos/psicologia/595-pedagogia-do-esportevivencia-e-aprendizagem-dos-jogos-esportivos-coletivos>. Acesso em: 20 out. 2011.

${ }^{2}$ PIRES, G. L. Breve introdução ao estudo dos processos de apropriação social do esporte. Revista da Educação Física, n. 9, v. 1, p. 25-34, 1998.

${ }^{3}$ LEONARDI, T. J. Pedagogia do esporte: pressupostos para uma teoria da avaliação da aprendizagem. 2013. Dissertação (Mestrado em Educação Física) - Faculdade de Educação Física, Universidade Estadual de Campinas, Campinas, 2013.

${ }^{4}$ DE ROSE JUNIOR, D.; TRICOLI, V. Basquetebol: conceitos e abordagens gerais. In: (Org.). Basquetebol: uma visão integrada entre ciência e prática. Barueri: Manole, 2005.

${ }^{5}$ BAYER, C. O ensino dos desportos colectivos. Lisboa: Dinalivro, 1994.

${ }^{6}$ FERREIRA, H. B.; GALATTI, L. R.; PAES, R. R. Pedagogia do esporte: considerações pedagógicas e metodológicas no processo de ensino-aprendizagem do basquetebol. In: PAES, R. R; BALBINO, H. F. (Org.). Pedagogia do esporte: contextos e perspectivas. Rio de Janeiro: Guanabara Koogan, 2005.

${ }^{7}$ DE ROSE JUNIOR, D. Modalidades esportivas coletivas: basquetebol. In: (Org).

Modalidades esportivas coletivas. Rio de Janeiro: Guanabara Koogan, 2006.

Conexões: revista da Faculdade de Educação Física da UNICAMP, Campinas, v. 11, n. 3, p. 147-165, jul./set. 2013. ISSN: 1983-9030 
${ }^{8}$ PAES, R. R.; MONTAGNER, P. C.; FERREIRA, H. B. Pedagogia do esporte: iniciação e treinamento em basquetebol. Rio de Janeiro: Guanabara Koogan, 2009.

${ }^{9}$ OFFICIAL BASKETBALL RULES $2010 . \quad$ Disponível em: <http://www.fiba.com/downloads/Rules/2010/OfficialBasketballRules2010.pdf>. Acesso em: 25 fev. 2011.

${ }^{10}$ YIN, R. K. Estudo de caso: planejamento e método. 2. ed. Porto Alegre: Bookman, 2001.

${ }^{11}$ GIL, A. C. Como elaborar projetos e pesquisa. 3. ed. São Paulo: Atlas, 1995.

${ }^{12}$ LEFÈVRE, F.; LEFÈVRE, A. M. C. O discurso do sujeito coletivo: um novo enfoque em pesquisa qualitativa. Caxias do Sul: Ed. da EDUCS, 2003.

${ }^{13}$ HERNÁNDEZ MORENO, J. et al. La iniciación a los deportes de equipo de cooperacíon/ oposición desde la estrutura y dinâmica de la accioón de juego: um nuevo enfoque. Lecturas: Educación Física y Deportes, ABuenos Aires, ano 6, n.33, 2001.

${ }^{14}$ PAES, R. R.; MONTAGNER, P. C.; FERREIRA, H. B. Pedagogia do esporte: iniciação e treinamento em basquetebol. Rio de Janeiro: Guanabara Koogan, 2009.

Recebido em: 20 jun. 2013 Aceito em: 28 ago. 2013 Contato: Heitor de Andrade Rodrigues triheitor@yahoo.com.br 